\title{
ALLEY ACTIVATION: GENIUS LOCI TO CONSTRUCT A RESILIENT CITY
}

\author{
Khilda Wildana NUR (10* \\ Department of Architecture, Faculty of Engineering, Muhammadiyah University of Makassar, \\ Makassar, Indonesia
}

Received 04 September 2019; accepted 20 February 2020

\begin{abstract}
Alleys in urban areas have recently been associated with crime and slums. Makassar as one of the biggest cities in Indonesia started to revitalize its alleys in 2014 as a campaign agreement implemented in Makassar Spatial Plan as well as an urban mutual interaction. This scheme is to change negative perspectives about alleys and to enhance urban community awareness. The research is a qualitative method with a phenomenological paradigm referring to urban design toolkits. Data collecting uses observation surveys and walk-through analyses. The selected alleys that have been discussed are based on thematic alleys from the government decisions. The findings show that successful government programs should empower the inheritance of cultural values. Genius loci adapted from the local nomenclature programs are more recognizable in public to build sense of belonging and promote urban resilience. The revitalization of alleys provide communal space, urban farming harvest, and leads to green economy improvements, settlement arrangements, and mutual local aids. Constructing urban resilience through government programs that should not depend on a Mayor's tenure is another finding in this research. Adaptive governance is essential in flexible and collaborative management rather than application programs in terms of political interests, beautification, and ceremonial activities.
\end{abstract}

Keywords: alley, Makassar, activation, genius loci, urban, resilience.

\section{Introduction}

A resilient city can suggest a strategic issue to cope with climate changes and detrimental effects on global lives. Thus, all stakeholders should participate in this issue in terms of households, housings, settlements, districts, and cities as these places are predicted to be homes for $60 \%$ people on this planet in 2030. Based on UN-Habitat (2013), cities will take up 2\% of the Earth's land mass and generate between $30 \%$ and $40 \%$ of the total emissions. Urban resilience is an urgently holistic action to tackle social, economic, and environmental problems. Shortly, both dynamic and informal settlements need to be upgraded and transformed into more secure and prosperous communities (Seeliger \& Turok, 2013). D’ Ascanio et al. (2016) stated that urban resilience provides the transition from a redevelopment model to an urban regeneration model, which actively involves the community actively and environmentally and involves the consumption of resources friendlily, aiming at reducing human activity impacts.

One of the community involvements related to urban regeneration is the value of local wisdom. The essence of place and the application of human's life included in the local wisdom are called genius loci (Norberg-Schulz, 2019). Loci are also associated with the spiritual sense of place in order to contextually sustain and preserve the quality of life and the local characteristics. The concept of genius loci has a significant role to create a city resilience.

The form of resilient cities can be assessed by following some indicators applied in land use of city areas. The settlement area has at least $60 \%$ of all land uses in a city. Thus, it is a mutual point to build urban resilience starting from settlement sectors. In fact, the typology of settlement and city structure varies in different cities. The American cities seem to have a grid district shape divided into super blocks and roads, avenues, streets, and other types of line ways. The European countries have developed their city structures in some various forming types of garden cities, axes and centre patterns, canal orientations, and some areas based on land use hierarchy and developed plans. These phenomena are not seen in Indonesia. Although Indonesia used to be colonized by The Netherlands, the city structure form is not actually parallel with the spatial plans of Dutch municipality. The concept of Dutch spatial plans is, in fact, applied in the city center for governmental

${ }^{*}$ Corresponding author. E-mail: khildawildananur@unismuh.ac.id 
functions, commercial districts, and cultural settlement districts, especially China Town, Arabic District, and Malay Kampong in Makassar. However, these plans are not found in the second layer, such as semi urban settlements and local community loci. The settlement concept has sporadic patterns oriented to rivers, roads, elevations, and the roles of local rules. These irregular settlement patterns eventually form cul-de-sacs and dead-end streets. Consequently, the line ways become paths or alleys since they are the most legible elements of the city image. An alley is now an important component divided into solid and void spaces. According to Lynch (1960), the sense of place creation is influenced by path, edge, node, landmark, and district. The alley can simply be assumed as a path, a component to construct city characteristics.

Toole (2012) mentioned that the alleys in Europe become traditional forms of urbanism, meaning to carry people. People call mews in London, Paris has arcade passages, and Japanese say roji, which basically means small streets. The Melbourne laneways are called capillaries, while streets and boulevards are arteries. On the other hand, the alleys in Indonesia represent public spaces of local community and settlement, especially in an informal settlement named Kampong that can reveal social, community, and broader governance responses to resilience (Jones, 2017). Kampong is a form of indigenous settlement developed without a planning process and inhabited mostly by lower middle-income groups (Setijanti et al., 2016). Furthermore, Damayanti and Kossak (2016) described that Indonesian kampongs are the third spaces with specifically social conditions as a result of cultural hybridizations and historical layers. Generally speaking, kampong is a frame of alleys and communal spaces promoting a defensibly shared space for people and a closeknit community fabric leading itself to resilient community networks (Shirleyana et al., 2018, and Octarina, 2018).

As a part of city structure, the alley has become an assessment purpose in terms of urban conditions. Some improvement programs such as alley greening and activating have been conducted in some Indonesian cities including Makassar, the metropolitan city in the eastern part. Based on Patel and Nosal's summary (2016), there are at least two indicators of urban resilience that have strong relationship with alley activation. In the first place, It needs robust built environments to ensure safety in both private and public domains, and it should be supported by strong local government linkages with strong civil society and community networks in the second place. Furthermore, Sharifi and Yamagata (2014) added some major criteria that can be used as frameworks for urban resiliency assessments, namely infrastructure, security, environment, economy, and institutions. Alley greening is an activity involving ecological descent programs such as urban runoff mitigation and urban island heat reduction (Newell et al., 2013). Mahdavinejad and Amini (2011) revealed that the pseudo participation may result in pubic satisfaction in terms of design processes and renovation projects for cul- tural contexts in order to reach a better sustainable environment in the future.

Makassarese alleys are often associated with a highly dense population, crime, and slums. The alleys are apparently ignored by the city development that focuses only on central business districts and commercial areas. Moreover, the migration of new comers and commuters in Makassar mostly occupying the alleys for either temporary or permanent living spaces is induced by the lower rented cost. Therefore, the alley distribution in Makassar is mainly located in Northern area, which is the most populated.

There are 7520 Makassarese alleys distributed in 15 districts and 153 villages. Every alley has a specific characteristic. Some alleys have become built environments due to their characteristics and settlements. The alleys also became one targeting output of Makassar government programs, especially during the 2014-1019 tenure of Makassar Major. Through the alley activation, the effects on Makassar government programs should necessarily be reviewed and discussed in terms of their significant aspects. The programs may not only be beautification at a glance but also be nurture at last with a local population entity that can contribute to sustainable developments and urban resilient assets.

\section{Methods}

Typically, the method is a qualitative research with a phenomenological paradigm. The discussion method is conducted by referring to urban design toolkits. Data collecting is via observation surveys and walk-through analyses. The graphic recording is the key to observation surveys such as photographs, annotated sketches, and plans. A specific urban design questionnaire for the community is conducted to find out where the improvements are needed, and we focus on how to achieve them. It is based on the questions and answers in three sections: people (how can the people influence and shape the alley to construct a resilient city?); places (how can the physical forms of alley be activated in urban interaction developments?); and movement (how can the network of alleys help bring the local resilience?). Schuler (1996) argues that the characteristics of a public participation process should be community-based, reciprocal, contribution-based, accessible and inexpensive, and efficiently modifiable.

Technically, the selected alleys that need to be observed are based on social, economic, and cultural priority problems. Afterwards the purposive samplings are mapped. Prior to the alley assessments, there are some approaching activities involving public participations and sustainable developments assisted by the government and experts.

\section{Discussion}

\section{Advertisement of government visions}

Makassar is the capital city of South Sulawesi and the largest city in Indonesia eastern part with a population of ap- 
proximately 1.67 million. Makassar has an area of about $199.3 \mathrm{~km}^{2}$ consisting of both formal and informal settlements distributed in an agglomerate of old city, developing areas, and prospective districts. Makassar, since 1951, has been led by 15 mayors influencing the government policy and spatial planning. During H. Moh. Ramdhan Pomanto's incumbency, Makassar launched multi sector programs, namely Makassar Bersih Lorong or Makassar Cleans the Alleys (Mabello) and Alley Garden highlighted as the alley activations. Mabello in Makassarese means beautiful or full of decoration.

To achieve the revitalization goals of an alley, all counterparts related to the programs are required to reveal how the alleys can give functions (if it is revitalized) and what benefit the alleys will bring in a community or government. Makassar government's vision is to implement "World City for All", starting from an alley arrangement to later creating a global city. The alley activation processes are methodologically based on the public participations. In the first stage, the government, experts, and communities decide some selected alleys to meet the criteria of detrimental conditions, priorities, and commodities. Subsequently, the determination process is conducted by forum group discussion, and the result is implemented in some policies and regulations. Then, the selected alleys are analyzed to identify their strengths, weaknesses, opportunities, and threats to assist the planners to make their strategic plans and action policies. Lastly, the final stage implements all the plan designs for the alleys, and the design results will be monitored periodically. Of all the identified alleys, some have been mapped, while the others have not yet.

Alley activation in Makassar comprises the target and local learning processes. The alleys with specific purposes motivate local community to apply government programs and local empowerment. For instance, Ujung Tanah district, which is a highly populated area, has 7 areas of which are the heaviest slum condition, and this district with its theme "Family Planning" (Keluarga Berencana) has more alleys than the other districts in Makassar. The site of Ujung Tanah district represents improper housing conditions, the smallest incomes, the worst sanitation, lack of law awareness, and unstable social mentality. Meanwhile, Tallo district has 8 worst slum categories and has higher children birth rate than the other districts in Makassar. This district has many alley distributions with theme "Friendly Children". Insufficient open spaces in their neighborhood constraint the residents to occupy alleys as their recreational grounds for children.

Alley revitalization means to reconstruct the citizens. The scheme processes, empowered by stakeholders and proven by every occupant, are participated in the brainstorming and application ideas. The social cohesions among middle-income housings, slum settlements, and municipality are conducted even more than a temporary cooperation, and the framework of coordination among habitants will contribute to the city future plans. As this indication continues, the quantity of local community in alley activation is a potential asset in a local community to indirectly develop an urban resilience.

\section{Implementation of green economy}

Green economy is an integrated concept of economy system that aims at reducing environmental risks and ecological scarcities and achieving a sustainable development. Improving the local economy on potential settlements is one of the main challenges to realize the resilience. The informal economy sectors, such as home industries, contribute to livelihoods, provision of goods, and services to the marginal sectors. Hence, the informal and marginal sectors are the keys to green economy applications. The budget from the government is then added by the volunteers' aids from the local settlements and from Corporate Social Responsibilities (CSR). This principle has been applied in a livelihood concept of Alley Enterprise Agency (BULO/Badan Usaha Lorong) and the program of 5-R in order to scope Makassar Alley Activation.

BULO has working plans to optimize the alley home industries and to enhance public participations under the government supervision. When the first BULO program launched, many of the alley residents obviously did not have a home industry. Although they had one already, they experienced marketing and management problems. In collaboration with some institutions and agencies, the government and local experts ultimately suggest an urban farming to become a solution that can improve the environmental quality and insufficient green open space in the alleys. The residents are then attracted by the opportunity to grow production quality with their neighbors in alleys and to access the information of how to improve their growing techniques. There are several BULO urban farming options including rooftop garden, hydroponic plant, and vertical garden. A variety of plants supplied by Department of Maritime, Fishery and Agriculture includes fruit and vegetables seeds, fertilizer composts and soils. When the first experiments were conducted, the vegetation samples were unable to cope with the local climate and daily local interests. Some planting methods failed because the seeds were merely from the government, and some of the farmers ignored the land feasibility.

The 5- $\mathrm{R}$ program, on the other hand, means Reuse, Recycle, Reduce, Replace, and Replant. a) Reuse is an approach of less garbage that goes to the landfill, by using paper grocery bags rather than buying new ones, using dishes instead of disposable plastic utensils and plates. The alley farmers are also required to use poly bags and reusable media for planting process. $b$ ) Reduce is applied in a compost bin and setting aside a place in alley residents' yards where they can dispose certain foods and plant materials, c) Recycle is applied in items such as rubber, aluminum, and glass. All the materials can be indefinitely recycled since the process does not affect their structure. For example, the trace wheels can be put in a wall along the alleys as aesthetic elements, or aluminum sticks can 

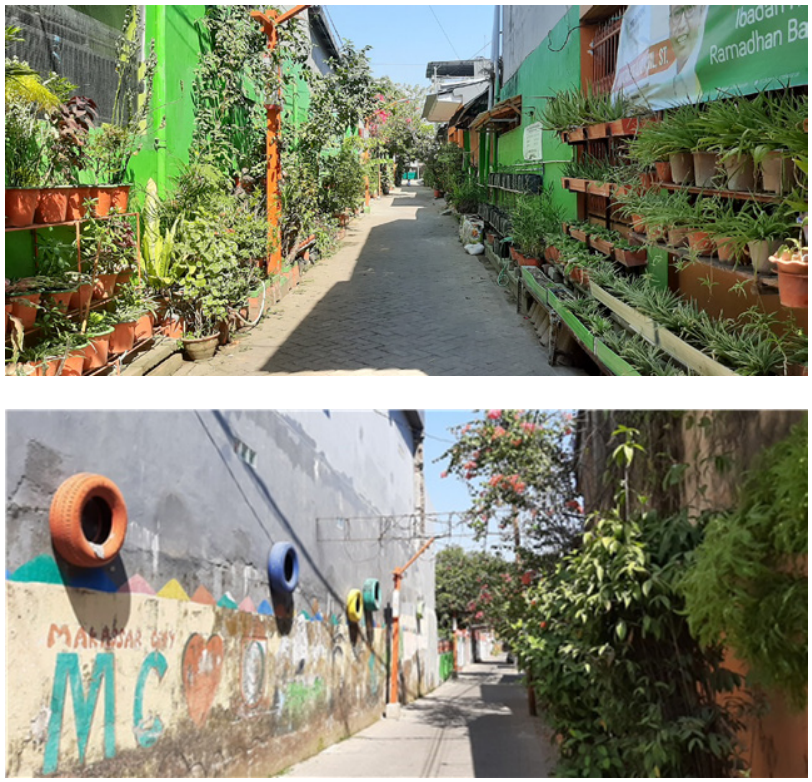

Figure 1. 5-R program and green economy application in alley revitalization

be decorated in main gates of alleys, d) Replant method is conducted through old plantings and using a hydroponic system in some vegetation such as cabbages, lettuces, and grapes. The implementation of green economy in some alleys in Tamalate District, Makassar can be seen in Figure 1.

\section{Local periodic festival and celebration}

An alley in settlement units is not only a circulation area but also a representative of diverse culture, a local population background, and an indicator of city development. Making the city more vibrant, alleys should be a part of significant programs in order to create a cellular channel of city construction. Furthermore, the spirit of alleys and occasional celebrations should be in accordance with the genius loci of certain communities.

In terms of alley activation contexts, Makassar government has an ambition to develop the community more sustainable through a harvest festival. After trial and error experiments of the green economy goal in various alleys, the pilot project in Kassi-kassi Alley of Tamalate District finally has its seasonal harvest from vegetable commodities such as tomatoes, grapes, chilies, and cabbages. This celebration motivates other communities to improve their own farming and increase their incomes. However, the financial costs and time consuming for urban farming in alleys need more attention from many stakeholders, but the farming itself has many advantages in a long term based on the surveys from the alley communities. The alley residents are now able to eat healthy vegetables and earn extra incomes.

\section{Fostering public engagement and cultural wisdom}

From physical aspects, alley activation has a clear appearance in terms of mural designs, planting methods, and paving patterns. Apart from this context, there are some valuable genius loci developed in alley activation. The intangible implementations of 4-Si from Makassarese and Buginese cultures: Sipakatau, Sipakainge, Sipakalebbi, and Sipatokkong have blended in a city locus. Sipakatau means a character without any level of people classification in terms of wealth and appearance. Sipakainge is an attitude to always remember other people in a right way. Sipakalebbi is associated with an attitude to appreciate other people in a good manner. Lastly, Sipatokkong is defined as cooperation. Togetherness and tolerance are such Indonesian traditional cultures that are rarely found among people living in urban alleys today. The privacy boundary in public areas, informal and marginal sectors, rich and poor level of society slightly decreases when residents living in alleys apply the rules of tolerance and togetherness. Alley spaces can also reduce social conflicts if 4-Si is seriously conducted. In addition, alleys as communal spaces can accommodate social capital activities in order to build a sense of place and experience public efforts, so the local authentic values still remain.

Another purpose of alley activation program is to minimize crime rate inter slum settlements. Many influencing factors are due to crime, but the lack of lightings in alley areas can trigger pedestrians' apprehension when strolling in the dark. Makassar government, therefore, add some street lightings with a program named "Sinarata" meaning "the light" from Makassarese. BySinarata" program, alley residents can now anticipate some unpredictable and uncomfortable conditions in public spaces and simultaneously publish the local tagline "Sinarata".

The use of Makassarese Mabello meaning cleaning alleys and Sinarata' meaning lighting as well as the local Values of 4-Si has built a sense of belonging, conserved the value of genius loci, and promoted the urban resilience. Therefore, the local community's participations are fundamental actions to create urban resilience in the future.

\section{Settlement improvement}

The commitment to realize alley activation should be followed by a public housing arrangement. To make this program come true, Makassar government creates Apparong (alley apartment), which is a vertical housing in an alley. The concept of Apparong is basically similar to ordinary apartments, but it uses different material elements. The size is also customizable based on the apartment ownerships. It is, unfortunately, until the mid of semester 2019, Apparong has still been on-going in some particular alleys. People in Makassar keep expecting the government's commitment to continue the program instead of just a political discourse.

A house can accommodate residents' activities, and an alley becomes a space to accommodate the activities together. In addition to a housing improvement, the government's typology of physical methods to activate alleys should, hence, include both pavement repairs and street ornaments. The first elements added at alleys' ends are the main gates for a signage, a pergola, or a vertical garden installed as an alley's ceiling. The gate design should not 
only an iconic and fundamental benchmark but a representative of one specific alley's vision. There are lightings and murals on the right and left side of the alley. The murals in an alley present an illustrative message to publics about some related family issues such as health, sexual harassment, drug abuse, and family education. Jumpandang Baru's alley can represent such an illustration. This alley has a theme of Family Planning Program (Keluarga Berencana). Impressing people through Graffiti and Mural is an effective education medium to reduce vandalism and makes a positive impact on changing the city's perspectives. For instance, graffiti as a public art in Toronto has emerged people's awareness in arts and has represented an object and ambience of the city. Located in Haji Lane Street, Singapore is a successful innovator to enhance its alley quality as an open-air gallery emphasizing a sense of vibrant city. Therefore, the public arts in some public housing walls in Makassar alleys are expected to be more interesting as a precedent for settlement arrangements.

Most alleys are located in slum areas and informal settlements in Makassar. These areas are also the locating targets for slum improvement programs by the Ministry of Public Works and Public Housing called KOTAKU programs. The improvement that has been done can utilize some corridors that are safe, visible, and convenient to use and to encourage pleasant ambience in alleys. The current proposal designs from KOTAKU and the local government for instance a monotonous trend of colorful theme, leaves another problem that needs to consider. The alley activation is merely to color the pavement surfaces with some particular patterns. Covering the pavements with massive materials like fully colorful paintings will damage the environment. The painting ingredients are so sensitive that can harm the alley's residents. The varicolored theme concept in the other cities of Indonesia seems to be a continuous trend of general designs without paying attention to artistic notions. This factual case has become a public polemic, so it is difficult to find an alley with a genuinely environmental and ecological design. The indicator for a beautification is only based on the multicolored theme that is less meaningful, less local wisdom, and without long term consideration (see Figure 2).

\section{Seasonal program based on leadership succession?}

Various projects have recently been implemented and developed in Makassar, aiming to reverse the trend of urban degradation and to incorporate the citizens assisted by the government and partnership financing agencies. The alley activation program is noted as an outstanding program since Makassar spatial plan was released. It was an initiative work by Makassar Mayor 2014-2019 referring to his agreement campaign. Apparently, this program has changed its direction after post-shifting of Makassar Major. Politically speaking, some policies and regulations have been substituted by new ones when the Mayor position was taken over. The public awareness and participation should be prioritized and should not depend heavily
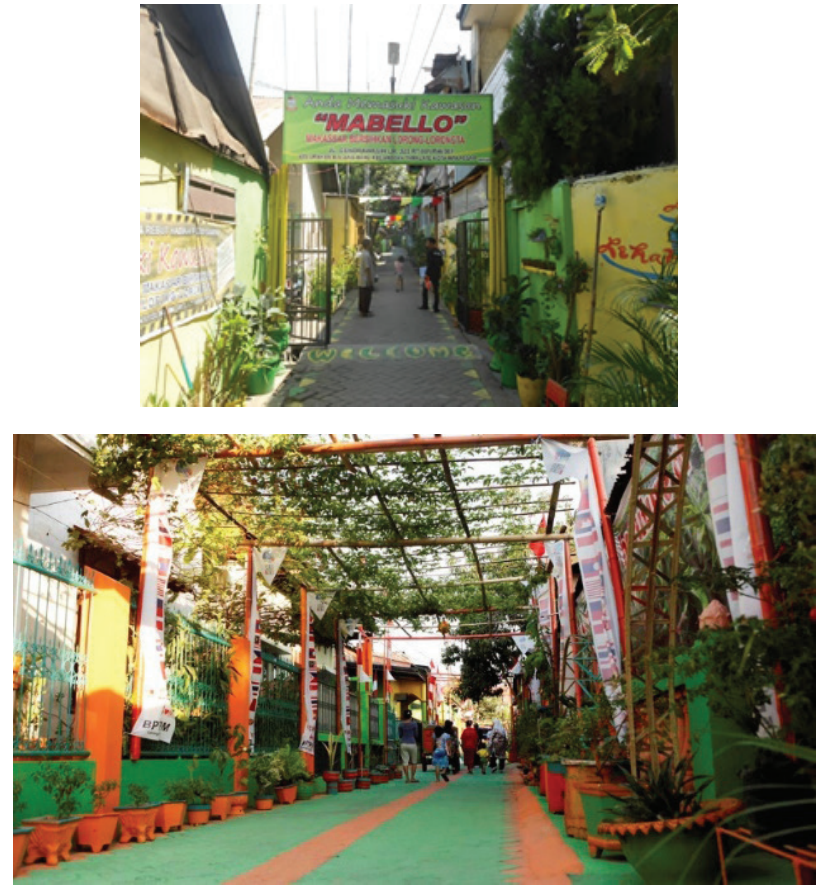

Figure 2. Urban settlement improvement and local wisdom publicity

on the leader's interests as to create a better city condition. From this situation, an adaptive governance is required to construct a flexible and collaborative management as well as a practical involvement.

From the first to the second year program, the alley activation involves social capital skills from experts, private sectors, and academicians. The student internship and apprentice programs are also conducted in the alleys, especially from the urban planners and architects' contributions. At the end of Mayor's period, this program is just a duty formality and ceremonial activity in society. Makassarese people tend to exercise a "wait and see" activity for a new Mayor's style of leadership in every election season. The spirit of place triggered by the alley activation can actually bridge the gap between the intangible and tangible elements during the Mayor's tenure. As a matter of fact, the physical elements can be seen in infrastructure developments, while non-physical elements can be approved from public services and regulation implementations. Thus, the citizens will easily identify the successful work programs based on either tangible or intangible elements during the certain Mayor's tenure.

\section{Conclusions}

Overall, the alley conditions vary in terms of physical and non-physical sectors using some applied programs to beautify landscape along the alleys, to rehabilitate pedestrian paths, and to light alley atmospheres. The alley activation is expected to support urban settlement improvements and also enhance urban farming productivity as an implementation of sustainable city integrated by economic, social, and environmental issues. 
The activation itself requires a comprehensive action from top down to bottom up strategies engaged with the government as a facilitator, the experts as a mediator, and the community as a user. The result is hoped to become a precedent for urban settlement improvement in the next settlement areas.

To make acceptable programs in public, the government intentionally use a tagline adopted from the local language and local cultural values as a part of genius loci. The alley activation is expected not only as a ceremonial activity but also as a sustainable program asset of urban resilience that should not depend entirely on a Mayor's succession.

\section{Acknowledgements}

The author's acknowledgement conveys to Major of Makassar period of 2014-2109, Mr. Ramdhan Pomanto who has delivered his explanation to experts and government's overview related to the research. For all the provision of data research, I am also grateful to all colleagues in PT. Dann Bintang Gelarrancana and Department of Architecture of Muhammadiyah University of Makassar. Any factual and interpretive errors are totally author's own.

\section{Funding}

This work was supported by the Department of Architecture, Faculty of Engineering, Muhammadiyah University of Makassar under Grant of Muhammadiyah University of Makassar - 2019.

\section{Author contributions}

Khilda Wildana Nur collected data and analysis of alley in Makassar. Muh. Rimba Arief supplied survey data in some particular alleys.

\section{Disclosure statement}

I do not have any competing financial, professional, or personal interests from other parties.

\section{References}

D’ Ascanio, F., Di Ludovico, D., \& Di Lodovico, L. (2016, May 18-20). Design and urban shape for a resilient city. Paper presented at the $2^{\text {nd }}$ International Symposium "New Metropolitan Perspectives" - Strategic Planning, Spatial Planning, Economic Programs and Decision Support Tools, Through the Implementation of Horizon/Europe 2020. Reggio Calabria, Italy.
Damayanti, R., \& Kossak, F (2016, March). Extending Kevin Lynch's concept of imageability in third space reading; case study of Kampungs, Surabaya-Indonesia. ITU A|Z, 13(1), 57-67. https://doi.org/10.5505/itujfa.2016.36349

Jones, P. (2017). Housing resilience and the informal city. Journal of Regional and City Planning, 28(2), 129-139. https://doi.org/10.5614/jrcp.2017.28.2.4

Lynch, K. (1960). The image of the city (Vol. 11). MIT Press.

Mahdavinejad, M., \& Amini, M. (2011). Public participation for sustainable urban planning in case of Iran. Procedia Engineering, 21, 405-413.

https://doi.org/10.1016/j.proeng.2011.11.2032

Newell, J. P., Seymour, M., Yee, T., Renteria, J., Longcore, T., Wolch, J. R., \& Shishkovsky, A. (2013). Green Alley Programs: planning for a sustainable urban infrastructure? Cities, 31, 144-155. https://doi.org/10.1016/j.cities.2012.07.004

Norberg-Schulz, C. (2019). Genius loci: towards a phenomenology of architecture (1979). Historic Cities: Issues in Urban Conservation, 8, 31.

Octarina, F. (2018). Shared space and culture of tolerance in Kampung settlements in Jakarta. https://doi.org/10.5614/sostek.itbj.2018.17.3.9

Patel, R., \& Nosal, L. (2016). Defining the resilient city. United Nations University, Centre for Policy Research, USA.

Seeliger, L., \& Turok, I. (2013). Averting a downward spiral: building resilience in informal urban settlements through adaptive governance. Environment and Urbanization, 26(1), 184-199. https://doi.org/10.1177/0956247813516240

Setijanti, P., Santosa, H., Krisdiato, J., Salatoen, M., Firmaningtyas, S., Ernawati, R., \& Bahari, F. K. (2016). Kampung development for resilient city. In K. Kähkönen, \& M. Keinänen (Eds.), Creating built environments of new opportunities. Paper presented at the Proceedings of the CIB World Building Congress 2016 (Vol. 1). Tampere University of Technology.

Sharifi, A., \& Yamagata, Y. (2014). Resilient urban planning: major principles and criteria. Energy Procedia, 61, 1491-1495. https://doi.org/10.1016/j.egypro.2014.12.154

Shirleyana, S., Sunindijo, R. Y., \& Hawken, S. (2018). City of Kampung: risk and resilience in the urban communities of Surabaya, Indonesia. International Journal of Building Pathology and Adaptation. https://www.researchgate.net/publication/328078609

Schuler, D. (1996). New community networks: Wired for change. Addison-Wesley.

Toole, D. (2012). Why alleys deserve more attention. https://www.citylab.com/design/2012/02/why-alleys-deserveyour-attention/1249/

UNHabitat. (2013). Urban planning for city leaders. https://www.mypsup.org/library_files/downloads/Urban $\% 20$ planning\%20for\%20city\%20leaders.pdf 